\title{
Coffee and tea consumption and the prevalence of coronary heart disease in men and women: results from the Scottish Heart Health Study
}

\author{
C A Brown, C Bolton-Smith, $M$ Woodward, H Tunstall-Pedoe
}

\begin{abstract}
Study objectives-The aim was to determine if there was a relationship between coffee or tea consumption and the prevalence of coronary heart disease in Scotland.

Design-The relationship between self reported coffee and tea consumption and the prevalence of coronary heart disease (history, symptoms, or electrocardiographic evidence) was investigated using multiple logistic regression analysis in the Scottish Heart Health Study (SHHS), a cross sectional study.

Setting-Twenty two Scottish districts were surveyed for the SHHS between 1984 and 1986.

Subjects-A total of 10359 men and women aged 40-59 years were studied.

Measurements and main results-Of the 9740 subjects who were assigned a category, $21.8 \%$ (2122) were classified as having indications of coronary heart disease. Men and women were combined in the odds ratio analysis because they showed almost identical patterns in the prevalence of coronary heart disease across the coffee and tea quarters (grouped according to consumption). Those who did not drink coffee had a significantly higher $(p<0.05)$ prevalence of coronary heart disease than the three groups for coffee drinkers. Adjustments for risk factors including cigarette smoking, total blood cholesterol, and diastolic blood pressure did not remove the significance of the odds ratios. There was a positive doseresponse effect between tea consumption and coronary heart disease which was removed after adjustment for various risk factors.

Conclusions-These findings do not support a positive relationship between coffee or tea consumption and coronary heart disease in this British study where most coffee consumed is instant coffee.
\end{abstract}

f Epidemiol Community Health 1993; 47: 171-175

Cardiovascular Epidemiology Unit, Ninewells Hospital and Medical School, Dundee DD1 9SY.

C A Brown

C Bolton-Smith

M Woodward

$\mathrm{H}$ Tunstall-Pedoe

Correspondence to: Mr C A Brown consumption and heart disease ${ }^{2-6}$ and others no effect. ${ }^{7-12}$ Most coffee consumed in Scotland is
Instant coffee is weaker than coffee made by other methods in terms of both caffeine ${ }^{14}$ and other constituents that determine flavour.

Many recent studies have investigated the link between the serum cholesterol concentration, a recognised risk factor for $\mathrm{CHD}$, and coffee consumption, and a positive relationship has been shown by many. ${ }^{15-24}$ These relationships are more noticeable in Scandinavian countries where boiled coffee is the preferred method of preparation, whereas filter coffee seems to have little ${ }^{22}$ or no effect on cholesterol values. ${ }^{20232526}$ Zock et al ${ }^{27}$ showed that this may be because a lipid factor, which is responsible for raising blood cholesterol, is high in boiled coffee but low in other forms of coffee. Tea consumption, which is traditionally high in the UK, has shown no relationship with $\mathrm{CHD}^{2} 51928$ or blood cholesterol concentrations. ${ }^{15} 171921$

This analysis uses data from a cross sectional study of CHD risk factors, the Scottish Heart Health Study (SHHS), ${ }^{29} 30$ to investigate whether coffee (predominantly instant coffee) and tea consumption influence the prevalence of CHD in Scotland. Such an investigation has not previously been reported in the UK.

\section{Methods}

The data used in this study were collected as part of the SHHS, which has been well documented elsewhere. ${ }^{31}$ Briefly, a cross sectional sample of 10359 men and women aged 40-59 years were randomly selected from 22 districts across Scotland. Each subject was sent an extensive questionnaire to complete at home. This included standard questions on sociodemography, past medical history, chest pain, ${ }^{32}$ smoking, ${ }^{33}$ and personality type (Bortner score). ${ }^{34}$ Food intake was assessed using a frequency questionnaire ${ }^{35}$ which has been validated in the SHHS population. ${ }^{36}$ Coffee and tea consumption was reported as the number of cups usually drunk per day. Respondents were invited to attend for a physical examination. Measurement of weight, height, blood pressure, 12 lead electrocardiogram (ECG), and the biochemical parameters (including serum cholesterol) have been detailed previously. ${ }^{29}$ The body mass index was calculated as weight $(\mathrm{kg}) /$

Subjects were grouped initially into three 'diagnosed' cases were those who had a self reported past medical diagnosis of either angina or myocardial infarction. CHD 'undiagnosed' cases height $^{2}(\mathrm{~m})$. categories of coronary heart disease status. CHD were determined by their positive response to the Rose chest pain questionnaire or the occurrence of a Q/QS pattern (Minnesota codes 1.1-1.2) or

ischaemic changes (Minnesota codes $1 \cdot 1-3$, looking at CHD the coffee consumed was mainly boiled, filtered, or percolated ground coffee. showing a positive relationship between coffee

Interest in the possible link between coffee continued since Paul et al ${ }^{1}$ first proposed that a high consumption of coffee was related to the later development of CHD. Many groups have sub- 
$4 \cdot 1-4,5 \cdot 1-3,7 \cdot 1)$ on the ECG, ${ }^{33}$ or both. The 'undiagnosed' cases had no past medical history of heart disease. The 'controls' were the remaining cases, excluding those with a history of taking drugs for cardiovascular disease or hypertension whose CHD status was ambiguous.

\section{STATISTICAL METHODS}

Self reported coffee and tea consumption was grouped into approximate quarters: $0,1-2,3-4$, and $\geq 5$ cups/day. The $\chi^{2}$ test was used initially to assess whether patterns of coffee and tea consumption differed between the diagnosed and undiagnosed groups, and then to determine if differences between the combined CHD group (diagnosed plus undiagnosed) and the control group were statistically significant. Coffee and tea consumption was also summed and grouped into approximate quarters: $\leq 4,5-6,7-8$, and $\geq 9$ cups/day. The $\chi^{2}$ test was then used to assess whether combined consumption differed between CHD cases and controls. Coffee consumption was compared with tea consumption using Spearman's rank correlation coefficient. Further correlations between CHD risk factors and the number of cups of coffee and tea drunk a day were performed using Pearson's correlation coefficient. Two tailed significance tests were performed in all the correlation analyses.

On the basis of these initial tests, multiple logistic regression analysis was performed on the combined diagnosed and undiagnosed CHD cases using GLIM, ${ }^{37}$ to calculate odds ratios (ORs) with $95 \%$ confidence interval (CI) for each coffee quarter and each tea quarter relative to the lowest consumption quarter. These ORs were further adjusted for age, diastolic blood pressure, serum total cholesterol, smoking group (never,

Table I Distribution of coronary heart disease diagnosed and undiagnosed groups by coffee and tea consumption quarters for men and women

\begin{tabular}{|c|c|c|c|c|}
\hline \multirow{2}{*}{$\begin{array}{l}\text { Coffee } \\
\text { consumption } \\
\text { (cups/day) }\end{array}$} & \multicolumn{2}{|l|}{ Men } & \multicolumn{2}{|l|}{ Women } \\
\hline & $\begin{array}{l}\text { Diagnosed } \\
(\%(\text { (no)) }\end{array}$ & $\begin{array}{l}\text { Undiagnosed } \\
(\%(n o))\end{array}$ & $\begin{array}{l}\text { Diagnosed } \\
(\%(\text { no }))\end{array}$ & $\begin{array}{l}\text { Undiagnosed } \\
(\%(\text { no }))\end{array}$ \\
\hline $\begin{array}{r}0 \\
1-2 \\
3-4 \\
\geq 5\end{array}$ & $\begin{array}{lr}37 \cdot 1 & (136) \\
36 \cdot 0 & (105) \\
36 \cdot 2 & (75) \\
33.9 & (63)\end{array}$ & $\begin{array}{l}62 \cdot 9(231) \\
64 \cdot 0(187) \\
63 \cdot 8(132) \\
66 \cdot 1(123)\end{array}$ & $\begin{array}{ll}27 \cdot 8 & (93) \\
24 \cdot 1 & (66) \\
16 \cdot 6 & (35) \\
20 \cdot 7 & (43)\end{array}$ & $\begin{array}{l}72 \cdot 2(242) \\
75 \cdot 9(208) \\
83 \cdot 4(176) \\
79 \cdot 3(165)\end{array}$ \\
\hline
\end{tabular}

Tea

consumption

(cups/day)

0

1-2

$1-2$
$3-4$
$\geq 5$

\begin{tabular}{|c|c|}
\hline $\begin{array}{l}34.9 \quad(38) \\
32.7 \quad(70) \\
39.0(119) \\
35.8(157)\end{array}$ & $\begin{array}{l}65 \cdot 1 \quad(71) \\
67 \cdot 3(144) \\
61 \cdot 0(186) \\
64.2(281)\end{array}$ \\
\hline
\end{tabular}

$19 \cdot 8 \quad(21)$

$\begin{array}{ll}24 \cdot 7 & (47) \\ 20 \cdot 7 & (61)\end{array}$

$20 \cdot 7$ (61)

(111) $\quad 75.4(340)$ $x^{2}=0.5, p=0.48$

Table II Distribution of coronary heart disease case and control groups by coffee and tea consumption quarters for men and women

\begin{tabular}{|c|c|c|c|c|}
\hline \multirow{2}{*}{$\begin{array}{l}\text { Coffee } \\
\text { consumption } \\
\text { (cups/day) }\end{array}$} & \multicolumn{2}{|l|}{ Men } & \multicolumn{2}{|l|}{ Women } \\
\hline & $\begin{array}{l}\text { Case } \\
(\%(n o))\end{array}$ & $\begin{array}{l}\text { Control } \\
(\%(\text { no }))\end{array}$ & $\begin{array}{l}\text { Case } \\
(\%(n o))\end{array}$ & $\begin{array}{l}\text { Control } \\
(\%(\text { no }))\end{array}$ \\
\hline $\begin{array}{r}0 \\
1-2 \\
3-4 \\
\geq 5\end{array}$ & $\begin{array}{r}27 \cdot 3(367) \\
21.7(292) \\
18 \cdot 6(207) \\
18 \cdot 7(180) \\
\chi^{2}=\end{array}$ & $\begin{array}{l}72 \cdot 7 \quad(979) \\
78 \cdot 3(1056) \\
81 \cdot 4 \quad(907) \\
81 \cdot 3 \quad(807) \\
\mathrm{p}<0.001\end{array}$ & $\begin{array}{r}27 \cdot 1(335) \\
20 \cdot 8(274) \\
19 \cdot 7(211) \\
18 \cdot 2(208) \\
\quad x^{2}=\end{array}$ & $\begin{array}{l}72 \cdot 9(903) \\
79 \cdot 2(1046) \\
80 \cdot 3 \quad(859) \\
81 \cdot 8 \quad(937) \\
p<0 \cdot 001\end{array}$ \\
\hline
\end{tabular}

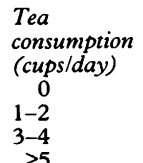

$x^{2}=35 \cdot 7, p<0.001$ ex-smoker, current smoker $<15,15-24$ and $\geq 25$ cigarettes/day), body mass index, total energy intake, percentage of energy from alcohol, dietary antioxidants and housing tenure. An antioxidant score which combined the dietary intake of vitamin $E$, vitamin $C$, and $\beta$-carotene by principal component analysis as derived by Bolton-Smith $e t$ $a l^{38}$ was used. Housing tenure (owner occupier $v$ renting) was used as the indicator of socioeconomic status, as it is the most discriminatory measure of social status in relation to CHD in Scotland. ${ }^{39}$ In the coffee analyses, adjustment was also made for tea consumption, while coffee was adjusted for in the tea analyses. The $\chi^{2}$ test was also used to assess whether overall and individual patterns of marital status, parental history of heart disease, adherence to a special diet, and self reported weight and exercise changes over the past year differed between those who did and did not drink coffee. Analysis of variance was used to test if the Bortner score differed between the two coffee groups. The rates were also standardised for age and housing tenure directly and the Bortner mean was adjusted for age and housing tenure using SPSS $^{x}{ }^{40}$

\section{Results}

Six per cent (619) of the 10359 men and women in the SHHS were excluded from this study because they had a relevant drug history without any indications of CHD. This left 9740 subjects (4897 men, 4843 women), of whom $6.4 \%$ were classed as diagnosed CHD (385 men, 240 women), $15.4 \%$ as undiagnosed CHD ( 684 men, 813 women), and $78.2 \%$ as controls ( $3828 \mathrm{men}$, 3790 women). Of these, $17 \cdot 3 \%$ of men and $22 \cdot 0 \%$ of women had at least one of the main risk factors missing and only those people with full risk factor data were included in the main adjusted OR analysis. Of the 4052 men in the OR analysis, $7 \cdot 8 \%$ were diagnosed CHD, $13.9 \%$ were undiagnosed $\mathrm{CHD}$, and $78.3 \%$ were controls. The percentages for the 3778 women were $4.3 \%$, $16.5 \%$, and $79 \cdot 2 \%$ respectively.

The only significant difference in the distributions of diagnosed and undiagnosed CHD for coffee and tea consumption quarters occurred for coffee consumption in women $(p=0.019)$, with the other distributions being clearly nonsignificant $(p>0.45)$ (table I). Since this was the only difference between the diagnosed and undiagnosed groups in this respect, the groups were combined for the rest of the analysis.

Table II shows the distribution of the CHD cases across the coffee and tea consumption quarters for men and women. In men, the prevalence of CHD is lower in the high coffee consumption groups compared with the low consumption groups $(27.3 \%$ in the lower quarter compared with $18.7 \%$ in the upper quarter). The pattern is very similar among women. The proportion of CHD cases by tea quarters shows the opposite pattern to that of coffee with a higher prevalence of CHD in the upper compared with the lower quarters for both men and women. Examination of the distribution of $\mathrm{CHD}$ cases across the combined coffee and tea cups/day found no significant differences (results not presented). The distribution of $\mathrm{CHD}$ cases across the consumption 
Table III Distribution of coronary heart disease case and control groups by coffee (coffee drinkers only) and tea (tea drinkers only) consumption quarters for men and women

\begin{tabular}{|c|c|c|c|c|}
\hline \multirow[b]{2}{*}{$\begin{array}{l}\text { Coffee drinkers only: } \\
\text { coffee consumption } \\
\text { (cups/day) }\end{array}$} & \multicolumn{2}{|l|}{ Men } & \multicolumn{2}{|l|}{ Women } \\
\hline & $\begin{array}{l}\text { Case } \\
(\%(n o))\end{array}$ & $\begin{array}{l}\text { Controls } \\
(\%(\text { no }))\end{array}$ & $\begin{array}{l}\text { Case } \\
(\%(n o))\end{array}$ & $\begin{array}{l}\text { Controls } \\
(\%(n o))\end{array}$ \\
\hline $\begin{array}{r}0 \\
1-2 \\
3-4 \\
\geq 5\end{array}$ & $\begin{array}{cc}25 \cdot 0 & (8) \\
25 \cdot 0 & (10) \\
12 \cdot 3 & (16) \\
20 \cdot 6 & (75) \\
& \chi^{2}\end{array}$ & $\begin{array}{l}75 \cdot 0 \quad(24) \\
75 \cdot 0 \quad(30) \\
87 \cdot 7(114) \\
79 \cdot 4(289) \\
p=0 \cdot 11\end{array}$ & $\begin{array}{rr}11 \cdot 1 & (4) \\
5.9 & (1) \\
20.5 & (16) \\
19 \cdot 4 & (84) \\
& X\end{array}$ & $\begin{array}{ll}88.9 & (32) \\
94 \cdot 1 & (16) \\
79 \cdot 5 & (62) \\
80.6 & (350) \\
, p=0.32\end{array}$ \\
\hline $\begin{array}{l}\text { Tea drinkers only: } \\
\text { tea consumption } \\
\text { (cups/day) } \\
0 \\
1-2 \\
3-4 \\
\geq 5\end{array}$ & $\begin{array}{lc}25 \cdot 0 & (8) \\
28 \cdot 9 & (22) \\
28 \cdot 6 & (94) \\
26 \cdot 8 & (243)\end{array}$ & $\begin{array}{l}75 \cdot 0 \quad(24) \\
71 \cdot 1 \quad(54) \\
71 \cdot 4(235) \\
73 \cdot 2(663) \\
p=0.91\end{array}$ & $\begin{array}{rr}11 \cdot 1 & (4) \\
27 \cdot 1 & (13) \\
28 \cdot 3 & (64) \\
27 \cdot 3 & (253) \\
& X\end{array}$ & $\begin{array}{l}88.9(32) \\
72.9 \quad(35) \\
71.7(162) \\
72 \cdot 7(674) \\
, p=0.18\end{array}$ \\
\hline
\end{tabular}

quarters for the whole sample and the subset of subjects with complete risk factor data was very similar (results not presented). No appreciable differences were observed in the distributions of cases across the coffee and tea consumption quarters when the analyses were performed separately for angina and myocardial infarction cases compared with all CHD cases (results not presented).

Table III shows a similar analysis to the previous table, but looks at coffee drinkers only and tea drinkers only. The pattern of CHD prevalence is similar to that in Table II for men, with lower CHD prevalence in the upper quarters, but this pattern is not seen for women. The pattern of increased CHD prevalence in the upper tea quarters, seen in table II, is reduced for men and sustained for women.

In table IV, Pearson's correlation coefficients were calculated between a number of CHD risk factors, and both coffee and tea consumption. Coffee consumption is most strongly associated with age $(p<0.001)$, with consumption declining with increasing age. Only total cholesterol and the antioxidant score are not significantly associated with coffee consumption, although when adjustment was made for age, cholesterol showed a strong positive relationship with coffee consumption (correlation coefficient $0.05, \mathrm{p}<0.001$ ).

Table IV Pearson's correlation coefficients for the coronary heart disease risk factors with the number of cups of coffee and tea consumed per day

\begin{tabular}{|c|c|c|}
\hline & Coffee & $T e a$ \\
\hline $\begin{array}{l}\text { Age }(\mathrm{y}) \\
\text { Total blood cholesterol }(\mathrm{mmol} / \mathrm{l}) \\
\text { Diastolic blood pressure }(\mathrm{mmH}) \\
\text { Body mass index }\left(\mathrm{kg} / \mathrm{m}^{2}\right) \\
\text { Total energy intake }(\mathrm{kcal}) \\
\% \text { Energy from alcohol } \\
\text { Antioxidant score } \\
\text { Cigarette consumption (no/day) }\end{array}$ & $\begin{array}{l}-0 \cdot 13^{\star \star \star} \\
0 \cdot 02^{\star} \\
-0 \cdot 09^{\star \star \star} \\
-0 \cdot 02^{\star} \\
-0 \cdot 02^{\star} \\
0 \cdot 03^{\star} \\
<0 \cdot 01^{\star \star \star} \\
0 \cdot 10^{\star \star}\end{array}$ & $\begin{array}{l}0 \cdot 13^{\star \star \star} \\
-0 \cdot 02^{\star} \\
<0 \cdot 01 \\
-0.01 \\
0 \cdot 16^{\star \star \star} \\
-0 \cdot 12^{\star \star \star} \\
0 \cdot 02^{\star} \\
0 \cdot 10^{\star \star \star}\end{array}$ \\
\hline
\end{tabular}

Table $V$ Odds ratios (95\% confidence interval) for coronary heart disease by coffee and tea consumption quarters

\begin{tabular}{|c|c|c|c|c|}
\hline $\begin{array}{l}\text { Coffee } \\
\text { consumption }\end{array}$ & Unadjusted & $\begin{array}{l}\text { Controlled } \\
\text { for tea }\end{array}$ & $\begin{array}{l}\text { Controlled for } \\
\text { all risk factors } \\
\text { (except housing } \\
\text { tenure) }\end{array}$ & $\begin{array}{l}\text { Controlled for } \\
\text { all risk factors }\end{array}$ \\
\hline $\begin{array}{r}0 \\
1-2 \\
3-4 \\
\geq 5\end{array}$ & $\begin{array}{l}1.00 \\
0.73(0.63,0.84) \\
0.63(0.54,0.73) \\
0.62(0.53,0.72)\end{array}$ & $\begin{array}{l}1.00 \\
0.75(0.65,0.87) \\
0.68(0.57,0.80) \\
0.68(0.56,0.83)\end{array}$ & $\begin{array}{l}1.00 \\
0.80(0.69,0.94) \\
0.76(0.63,0.90) \\
0.75(0.62,0.92)\end{array}$ & $\begin{array}{l}1.00 \\
0.83(0.72,0.97) \\
0.81(0.68,0.97) \\
0.81(0.67,0.99)\end{array}$ \\
\hline \multicolumn{5}{|c|}{$\begin{array}{l}\text { Tea } \\
\text { consumption }{ }^{\star \star}\end{array}$} \\
\hline $\begin{array}{l}0 \\
1-2 \\
3-4 \\
\geq 5\end{array}$ & $\begin{array}{l}1.00 \\
0.97(0.79,1.19) \\
1.12(0.93,1.36) \\
1.37(1.14,1.64)\end{array}$ & $\begin{array}{l}1.00 \\
0.96(0.78,1.18) \\
1.02(0.82,1.26) \\
1.09(0.88,1.36)\end{array}$ & $\begin{array}{l}1.00 \\
0.95(0.76,1.17) \\
0.98(0.79,1.23) \\
1.04(0.82,1.30)\end{array}$ & $\begin{array}{l}1.00 \\
0.97(0.78,1.21) \\
1.00(0.80,1.24) \\
1.05(0.84,1.33)\end{array}$ \\
\hline
\end{tabular}

Adjustment for age did not affect appreciably the correlation coefficients for the other risk factors (results not presented). Tea consumption is not significantly correlated with diastolic blood pressure or body mass index. Total energy intake, age, and blood cholesterol concentration show strong positive relationships with tea consumption, while the percentage of energy from alcohol is negatively associated with tea consumption.

The unadjusted and adjusted ORs (with 95\% CI) (adjustments made for risk factors in table IV) for having CHD according to coffee and tea consumption, relative to the lowest quarter, are shown in table $\mathrm{V}$ for men and women combined. The ORs for men and women separately were very similar (results not presented). The interaction between coffee and tea was examined, but no significant effect was found. The unadjusted ORs for CHD were significantly lower in the top three quarters compared with the lowest quarter $(p<0.05)$, and these ORs were not changed noticeably when adjusting for all the risk factors. Further adjustment for socioeconomic status (housing tenure) brought the ORs closer to unity, but did not remove the statistical significance. The unadjusted ORs (with $95 \% \mathrm{CI}$ ) for having CHD (diagnosed or undiagnosed) according to tea consumption relative to the lowest quarter showed the opposite pattern to that seen for coffee. The OR in the upper quarter was significantly higher $(p<0.05)$ than for the lowest quarter. This significance was lost when adjustment was made for coffee, but further adjustment for all the other risk factors had little additional effect. Again, the coffee and tea interaction was examined, but no significant effect was found.

Finally, subjects who did not drink coffee were compared with the coffee drinkers for a number of variables to try to identify any factors that could explain the higher level of CHD seen in the former group. Adjustment for age and housing tenure made little difference to the results unless stated. There was no difference in the proportion of subjects with a parental history of heart disease between those who did and did not drink coffee $(24.4 \% v 24.7 \%)$, or in the distribution of marital status between the two groups after adjustment for age and housing tenure. There was a significant difference $\left(\chi^{2}=34 \cdot 1, \mathrm{p}<0.001\right)$ in the distribution of those on special diets, with $8.5 \%$ of coffee drinkers on a slimming diet (mainly self prescribed) compared with $6 \cdot 8 \%$ of those who did not drink coffee. Altogether $44.2 \%$ of coffee drinkers compared with $37 \cdot 7 \%$ of those who did not drink coffee $\left(\chi^{2}=32.4, p<0.001\right)$ reported trying to lose weight in the past year, and $41.1 \%$ of the coffee drinkers compared with $36 \cdot 2 \%$ of those who did not drink coffee reported trying to take more exercise $\left(\chi^{2}=18.8, \mathrm{p}<0.001\right)$. The Bortner score was 169.3 among coffee drinkers compared with 159.9 in those who did not drink coffee $(\mathrm{F}=101.9, \mathrm{p}<0.001)$, and 167.4 compared with 161.9 , after adjustment for age and housing tenure.

\section{Discussion}

The finding of a small protective effect of coffee drinking on $\mathrm{CHD}$ has not previously been 
reported, although Grobbee et $a l^{12}$ reported no effect on CHD when controlling for all possible risk factors in a similar analysis. Cross sectional studies such as the SHHS are methodologically weaker than prospective studies, however, several prospective studies have controlled adequately for risk factors and found no relationship between increased coffee consumption and CHD. ${ }^{7-11}$ Some prospective studies $^{1346}$ have shown a positive dose-response between coffee consumption and CHD, but Paul et $a l^{1}$ and Lacroix et $a l^{3}$ failed to control for smoking and cholesterol respectively. Legrady $e t a l^{4}$ showed that those who drink $\geq 6$ cups of coffee/day have greater levels of CHD than those who drink $<6$ cups/day (relative risk 1.71), while Tverdal $e t a l$, in a five year follow up study, ${ }^{6}$ found double the rate of coronary deaths in those who drank a great deal of coffee ( $\geq 9$ cups/day) compared with non-coffee drinkers. Adjustment for various risk factors made little difference in either study. The Boston Collaborative Drug Surveillance Program, ${ }^{2}$ in a case-control analysis of myocardial infarction, found that those who drank five cups of coffee a day or more had twice the level of myocardial infarction than those who did not drink coffee. Jick et $a l,{ }^{28}$ from the same unit, showed similar findings. A prospective study by Klatsky et $a l^{5}$ found the relative risk of myocardial infarction was 1.4 in those who drank $\geq 4$ cups a day compared with those who did not drink coffee, although there was no effect seen for other coronary deaths. Again, adjustment for various risk factors in these studies made little difference.

Recent studies have investigated the effect of different types of coffee (boiled, filtered, instant) on serum cholesterol concentrations. A number have shown that those who drink a considerable amount of boiled coffee have noticeably higher serum cholesterol concentrations than low consumers of boiled coffee, whereas drinkers of filter coffee often show no difference in cholesterol concentrations between consumption groups. ${ }^{16} 202325-27$

In the UK, instant coffee is the most popular form of coffee. Few studies in the UK have investigated the effect of instant coffee on associated risk factors for CHD, and no major studies have. investigated the effect of instant coffee on CHD. Lee et al (personal communication), in an analysis of SHHS data, showed a significant increase in total blood cholesterol values with increasing coffee consumption for both men and women $(2 \%$ increase between 0 cups/day and 6 cups/day, $\mathrm{p}<0.05)$, after adjusting for a number of risk factors, although, this was not as noticeable as that seen in Scandinavian studies, ${ }^{16}{ }^{24}$ while two small trials showed no effect. ${ }^{41}{ }^{42}$ Mean coffee consumption in our study ( $2 \cdot 7 \mathrm{cups} /$ day) is similar to that in the USA ( 3 cups/day ${ }^{11}$ but much less than in Norway ${ }^{16}$ and Holland, ${ }^{23}$ where mean coffee consumption is 5 cups/day. It seems unlikely that coffee drinkers in Scotland are not consuming enough coffee to show any adverse effects on CHD, since the two studies from the Boston Collaborative Drug Surveillance Program, ${ }^{2}{ }^{28}$ with similar coffee consumption levels to the SHHS, found a positive relationship between myocardial infarction and increasing coffee consumption. It may be that the lipid factor reported to be responsible for the cholesterol raising effect of boiled coffee, ${ }^{27}$ may be only minimal in instant coffee. Thus, the widely different reported effects of coffee consumption on CHD may be explained if future studies measure and account for the active lipid factor.

Tea drinking is more common in the UK than coffee drinking, ${ }^{13}$ which is not the case in the USA and the rest of Europe. Subjects in our study had a mean tea consumption of 4 cups/day and those who drank little coffee, compensated by drinking tea (correlation coefficient $-0.62, \mathrm{p}<0.001$ ). This study, in common with the few others that have investigated tea consumption and $\mathrm{CHD}$, showed no relationship with either a diagnosis of $\mathrm{CHD}^{2528}$ or the serum cholesterol concentration. ${ }^{1519} 21$

The difference in patterns of CHD across the coffee and tea consumption quarters, with caffeine content in instant coffee and tea being very similar $(64.2 \mathrm{mg} /$ cup coffee compared with $55.2 \mathrm{mg} /$ cup tea ${ }^{14}$ would agree with the current wisdom that caffeine is not a risk factor for CHD. Grobbee et $a l^{12}$ found no relationship between total caffeine and CHD, thus the lack of information on cola consumption and other sources of caffeine in our study is unlikely to be important. There seems to be no relationship between total caffeine and the total blood cholesterol concentration. ${ }^{21}$

Coffee and tea consumption may not be accurately quantitated by the questionnaire method, since information on the cup size, strength, and type of coffee and tea consumed is unknown. We know from the Ministry of Agriculture, ${ }^{13}$ however, that approximately $75 \%$ of coffee consumed in the $\mathrm{UK}$ is of the instant variety and the estimated total volume of coffee and tea consumed in this study agrees well with recent results from the seven day weighed record survey of British adults. ${ }^{43}$ Changes in consumption over the years is unknown, although in this study, coffee consumption decreased with age, while tea consumption increased with age. The publicity from some studies of the adverse effect of coffee on CHD does not seem to have influenced the participants in our study, since little difference was reported between consumption patterns for the diagnosed and undiagnosed CHD groups.

Modest ${ }^{44}$ suggested that increased coffee consumption is not a cause of CHD, but rather a marker for increased stress, which is a risk factor for CHD. Those who drank at least a cup of coffee a day were found to have a significantly higher Bortner score (a possible indicator of stress) than the non-coffee drinkers. While coffee drinkers may suffer from more stress than their non-coffee drinking counterparts, it seems to have no effect on the prevalence of CHD in this population. Fewer of those who did not drink coffee reported trying to take more exercise or lose weight over the past year than coffee drinkers, and a higher proportion of coffee drinkers than those who did not drink coffee were on a slimming diet. These differences should not have biased the results unduly, since body mass index was controlled for in the main analysis. Thus, although it is possible that some other, undefined characteristic of those who do not drink coffee has contributed to their high risk of CHD compared with coffee drinkers, it does seem an unlikely explanation. 
In conclusion, while every effort has been made to control for possible confounding from the major and other putative risk factors for CHD in this analysis, a small protective effect of coffee on CHD risk is still seen. It is not appropriate to conclude that coffee prevents heart disease, but these results show no evidence to suggest a significant, positive independent relationship between coffee consumption and CHD in this predominantly instant coffee drinking population. We can confirm the previously reported lack of a relationship between tea consumption and risk of CHD.

The Scottish Heart Health Study was funded by the Scottish Office: Home and Health Department. The opinions expressed are those of the authors and not the funding body.

1 Paul O, Lepper MH, Phelan WH, Dupertuis GW, MacMillan A, McKean H, Park $\mathrm{H}$. A longitudinal study of coronary heart disease. Circulation 1963; 28: 20-31.

2 Boston Collaborative Drug Surveillance Program. Coffee drinking and acute myocardial infarction. Lancet 1972; ii: 1278-81.

3 Lacroix AZ, Mead LA, Liang KY, Thomas CB, Pearson TA. Coffee consumption and the incidence of coronary heart disease. N Eng 7 Med 1986; 315: 978-82.

4 Legrady D, Dyer AR, Shekelle RB, Stamler J, Liu K, Paul O, Lepper M, Shryock AM. Coffee consumption and mortality in the Chicago Western Electric Company Study. Am $\mathbf{f}$ Epidemiol 1987; 126: 803-12.

5 Klatsky AL, Friedman GD, Armstrong MA. Coffee use prior to myocardial infarction restudied: heavier intake may to myocardial infarction restudied: heavier intake

6 Tverdal A, Stensvold I, Solvoll K, Foss OP, Lund-Larsen P, Bjartveit K. Coffee consumption and death from coronary heart disease in middle aged Norwegian men and women. heart disease in middle

7 Dawber TR, Kannel WB, Gordon T. Coffee and cardiovascular disease: observations from the Framingham study. N Eng f Med 1974; 291: 871-4.

8 Hennekens $\mathrm{CH}$, Drolette ME, Jesse MJ, Davies JE, Hutchinson GB. Coffee drinking and death due to coronary heart disease. $N$ Engl $\mathcal{F}$ Med 1976; 294: 633-6.

9 Yano K, Rhoads GG, Kagan A. Coffee, alcohol, and risk of coronary heart disease among Japanese men living in Hawaii. N Eng f Med 1977; 297: 405-9.

10 Heyden S, Tyroler HA, Heiss G, Hames CG, Bartel A. Coffee consumption and mortality. Total mortality, stroke mortality, and coronary heart disease mortality. Arch Intem Med 1978; 138: 1472-5.

11 Wilson PWF, Garrison RJ, Kannel WB, McGee DL, Castelli WP. Is coffee consumption a contributor to cardiovascular disease? Insights from the Framingham Study. Arch Intern Med 1989; 149: 1169-72.

12 Grobbee DE, Rimm EB, Giovannucci E, Colditz G, Stampfer M, Willett W. Coffee, caffeine and cardiovasculer disease in men. N Eng $\mathcal{f}$ Med $1990 ; 323: 1026-32$.

13 Ministry of Agriculture, Fisheries and Food. Household food consumption and expenditure, 1988. London: HMSO, 1989.

14 Scott NR, Chakraborty J, Marks V. Caffeine consumption in the United Kindom: a retrospective study. Food Sciences and Nutrition 1989; 42F: 183-91

15 Little JA, Shanoff HM, Csima A, Yano R. Coffee and serum lipids in coronary heart disease. Lancet 1966; i: 732-4. 16 Thelle DS, Arnesen E, Forde OH. The Tromso heart study:
does coffee raise serum cholesterol? N Eng 7 Med 1983; 308: 1454-7.

17 Klatsky AL, Petitti DB, Armstrong MA, Friedman GD. Coffee, tea and cholesterol. Am $\mathcal{f}$ Cardiol 1985; 55: 577-8.

18 Williams PT, Wood PD, Vranizan KM, Albers JJ, Garay SC Taylor CB. Coffee intake and elevated cholesterol and apolipoprotein B levels in men. $¥ A M A 1985 ; 253$ : 1407-11.
19 Kark JD, Friedlander Y, Kaufmann NA, Stein Y. Coffee, tea and plasma cholesterol: the Jerusalem Lipid Research Clinic and plasma cholesterol: the Jerusalem Lipid R

20 Bonaa K, Arnesen E, Thelle DS, Forde OH. Coffee and cholesterol: is it all in the brewing? The Thromso stduy. BMF 1988; 297: 1103-4

21 Davis BR, Curb JD, Borhani NO, Prineas RJ, Molteni A Coffee consumption and serum cholesterol in the hypertension detection and follow-up program. $\mathrm{Am} f$ Epidemiol 1988; 128: 124-36.

22 Pietinen P, Geboers J, Kesteloot H. Coffee consumption and serum cholesterol: an epidemiological study in Belgium. In f Epidemiol 1988; 17: 98-104.

23 Bak AAA, Grobbee DE. The effect on serum cholestero levels of coffee brewed by filtering or boiling. $N$ Eng $\mathcal{F} \mathrm{Med}$ 1989; 321: 1432-7.

24 Solvoll K, Selmer R, Loken EB, Foss OP, Trygg K. Coffee, dietary habits, and serum cholesterol among men and women 35-49 years of age. Am ₹ Epidemiol 1989; 129: 1277-88.

25 Pietinen P, Aro A, Tuomilehto J, Uusitalo U, Korhonen $\mathrm{H}$ Consumption of boiled coffee is correlated with serum cholesterol in Finland. Int $₹$ Epidemiol 1990; 19: 586-90.

26 Schwarz B, Bischof HP, Kunze M. Coffee and cardiovascular risk: epidemiological findings in Austria. Int cardiovascular risk: epidemio

27 Zock PL, Katan MB, Merkus MP, Van Dusseldorp M Harryvan JL. Effect of a lipid-rich fraction from boiled coffee on serum cholesterol. Lancet 1990; 335: 1235-7.

28 Jick H, Miettinen OS, Neff RK, Shapiro S, Heinonen OP Slone D. Coffee and myocardial infarction. $N$ Eng $f$ Med 1973; 289: 63-7.

29 Smith WCS, Tunstall-Pedoe H, Crombie IK, Tavendale R Concomitants of excess coronary deaths: major risk factor and lifestyle findings from 10359 men and women in the Scottish Heart Health Study. Scott Med f 1989; 34: 550 555.

30 Tunstall-Pedoe $\mathrm{H}$, Smith WCS, Crombie IK, Tavendale $\mathrm{R}$. Coronary risk factor and lifestyle variation across Scotland: results from the Scottish Heart Health Study. Scott Med $\mathcal{f}$ 1989; 34: 556-60.

31 Smith WCS, Crombie IK, Tavendale R, Irving JM, Kenicer MB, Tunstall-Pedoe H. The Scottish Heart Health Study: objectives and development of methods. Health Bull 1987 45: 211-7.

32 Rose G, McCartney P, Reid DD. Self-administration of questionnaire on chest pain and intermittent claudication. Brit $\mathcal{F}$ Prev Soc Med 1977; 31: 42-8.

33 Rose GA, Blackburn H, Gillum RF, Prineas RJ. Cardiovascular survey methods. Geneva: World Health Organisation, 1982.

34 Bortner RW. A short rating scale as a potential measure of pattern A behaviour. fournal of Chronic Diseases 1969; 22 $87-89$.

35 Yarnell JWG, Fehily AM, Milbank JE, Sweetnam PM Walker CL. A short dietary questionnaire for use in an epidemiological survey. Comparison with weighed dietary
records. Human Nutrition: Applied Nutrition 1983; 37: $103-12$

36 Bolton-Smith C, Smith WCS, Woodward M, TunstallPedoe $\mathrm{H}$. Nutrient intakes of different social class groups: Results from the Scottish Heart Health Study (SHHS). BrF Nutr 1991; 65: 321-35.

37 Generalised linear interactive modelling manual. In: CD Payne, ed. London: Royal Statistical Society, 1987.

38 Bolton-Smith C, Woodward M, Tunstall-Pedoe $H$. The Scottish Heart Health Study. Dietary intake by food frequency questionnaire and odds ratios for coronary hear frequency questionnaire and odds ratios for coronary heart disease risk. II. The antioxidat
Clin Nutr 1992; 46: 85-93.

39 Woodward M, Shewry MS, Smith WCS, Tunstall-Pedoe H. Social status and coronary heart disease: results from th Scottish Heart Health Study. Prev Med 1992; 21: 136-148.

40 SPSS $^{x}$ users guide, edition 3. Chicago: SPSS Inc, 1987.

41 Hill C. Coffee consumption and cholesterol concentrations (letter). BMJ 1985; 290: 1590

42 Aro A, Kostiainen E, Huttunen JK, Seppala E, Vapaatalo H. Effects of coffee and tea on lipoproteins and prostanoids. Artherosclerosis 1985; 57: 123-8.

43 Gregory J. Foster K, Tyler H, Wiseman $\mathrm{M}$. The dietary and nutritional survey of British adults. Office of Population Censuses and Surveys, London: HMSO, 1990.

44 Modest G. Coffee consumption and the incidence of coronary heart disease (letter). $N$ Eng $\mathcal{F}$ Med 1987; 316: 945-6. 